$$
\text { "tmcs-baranyai-report" — 2011/5/16 — 12:55 — page } 159 \text { — \#1 }
$$

\title{
Report of Meeting Researches in Didactics of Mathematics and Computer Sciences January 28 - January 30, 2011, Satu Mare, Romania
}

\author{
Compiled by T. BARAnYAi And E. Herendiné Kónya
}

Abstract. The meeting Researches in Didactics of Mathematics and Computer Science was held in Satu-Mare, Romania from the $28^{\text {th }}$ to the $30^{\text {th }}$ of January, 2011. The 46 Hungarian participants - including 34 lecturers and $12 \mathrm{PhD}$ students - came from 3 countries, 14 cities and represented 20 institutions of higher education. The abstract of the talks and the posters and also the list of participants are presented in this report.

Key words and phrases: new methods in teaching, experiments in teaching, talent care, history of mathematics, geometry and its practical applications, the use of computers in teaching mathematics.

ZDM Subject Classification: A60.

The meeting Researches in Didactics of Mathematics and Computer Science was held in Satu-Mare, Romania from the $28^{\text {th }}$ to the $30^{\text {th }}$ of January, 2011 at the Satu-Mare Teacher Training College of the Babeş-Bolyai University. It was organized by the PhD School of Mathematics and Computational Sciences of the University of Debrecen, the Kölcsey Ferenc Teacher Training College of the Reformed Church of Debrecen and the Satu-Mare Teacher Training College of the Babeş-Bolyai University.

The 46 Hungarian participants - including 34 lecturers and $12 \mathrm{PhD}$ students - came from 3 countries, 14 cities and represented 20 institutions of higher education.

Copyright (C) 2011 by University of Debrecen 


$$
\text { "tmcs-baranyai-report" — 2011/5/16 — 12:55 — page } 160 \text { — \#2 }
$$

The conference was opened by senior lecturer Balázs Béla Végh PhD, director of studies of the Satu Mare Department of the Babeş-Bolyai University, who after greeting the participants of the conference expressed his pleasure to host the well-established international conference. On behalf of the organizers, professor Zsolt Páles, vice-rector of the University of Debrecen, leader of the PhD School of Mathematics and Computational Sciences welcomed the participants and emphasized the importance of the fact that the conference was held this year at a new location in Transylvania.

The subjects presented in the lectures and posters of the conference were of great variety. Apart from the researches on the history of mathematics, geometry, didactics of mathematics, the use of alternative methods in teaching mathematics, there were several lectures on different subjects in computer science.

Among the cultural programmes offered by the conference we could mention the sightseeing in the historical center of Satu Mare and the Saturday evening concert given by the Rock Theatre of Northern Hungary at the Philharmonic Hall.

In his closing speech, professor Gyula Maksa, leader of the Didactic Program of the PhD School of Mathematics and Computational Sciences appreciated the high quality of the lectures, with special regard to the works of the $\mathrm{PhD}$ students. He also gave his thanks to the lecturers and to the organizers Tünde Baranyai PhD, Sándor Kiss PhD and Eszter Herendiné Kónya PhD, whose work contributed to the success of the conference.

Subsequently, we provide the abstracts of the lectures and posters in alphabetical order, followed by the names and contact data of the authors:

\author{
Abstracts of talks \\ How we used an interactive whiteboard in descriptive geometry \\ Adrien Árvainé Molnár - Sarolta Fazekas \\ DE MK \\ E-mail: mazg@freemail.hu, sarolta.fazekas@gmail.com
}

An experiment has been conducted at the Technical College to improve the teaching efficiency in use. Our aim is to establish a new visual methodology and educational system building upon the geometry knowledge gained in the secondary schools, by conforming to the objectives and tone of the education at the higher schools. A geometry program - called Geogebra - has been used to create education materials presented to the students using interactive tables. The 
"tmcs-baranyai-report" — 2011/5/16 — 12:55 — page 161 — \#3

efficiency of this methodology, the acceleration of the students' motivation and activity has to be improved and measured advancing the appreciative learning. The perspective visionary need to be greatly aided by putting the focus onto the demonstrating figures founding the competency for all advanced seminars. Our results and experience has been collected and presented into this article.

Examination of mathematics schoolbooks in use in Hungarian primary schools in Romania

Tünde Baranyai - Gabriella Stark

Babeş-Bolyai University, Faculty of Psychology and Pedagogical Sciences, Satu

Mare, Romania

E-mail: baratun@yahoo.com, ngabriella77@yahoo.com

A good schoolbook must meet a number of pedagogical, psychological, scientific, aesthetical, and other requirements. The presented research examines whether the mathematics schoolbooks in use in Hungarian primary schools in Romania meet those requirements. We used documentation, contents analysis and surveys as research methods.

We examined the mathematics schoolbooks according requirements in appearance, style and language, editing, approach and contents material. Following contents analysis we can mention as a positive outcome that the schoolbooks provide a great variety of problem solving tasks, while meeting the principle of progressivity. Nevertheless they contain mathematical mistakes, scientific inaccuracies, are not in total agreement with the curriculum and their language is inappropriate. These findings are supported by the results of our survey. The hundred and two teachers asked in the survey gave a medium qualification to the primary school mathematics schoolbooks. The most often quoted flaws are the lack of differentiated, level based and task based teaching material, as well as the inappropriate language owed to bad translation of the schoolbooks originally written in Romanian.

Development of mathematical skill and measurement possibilities of its using computer

Ignác Bontovics

SZIE - PK, Szarvas

E-mail: bignacz@gmail.com

Computer and internet usage is an integral part of our lives and also education. Already in primary school children can use computer with an appropriate 


$$
\text { "tmcs-baranyai-report" — 2011/5/16 — 12:55 — page } 162 \text { — \#4 }
$$

routine and pleased to be working on it. This can be exploited to make some flash-based applications, which allows measuring and developing mathematical skills of primary school children on different part of math - according to possibilities. Up to now tasks were made for topics mathematical logic, space perception, probability and combinatory. These interactive tasks help to see better the given space and its mastery of skills. So far completed animation can be seen on my http://www.bontovics.hu website, on research menu. Completed animations exe executable format can be also downloaded, so they can be used without an internet.

Building and coding algorithms in spreadsheet applications Mária Csernoch

University of Debrecen, Department of Information Technology, Debrecen, Hungary

E-mail: csernoch.maria@inf.unideb.hu

We have to face the fact that with the increasing number of computer users the number of those high school students who are willing to do programming does not increase. The standard methods for teaching programming languages do not work in mass education. Consequently, we have to introduce new methods with which we could draw the attention of those towards programming who are application users. One of the possibilities is that the popular office applications, especially spreadsheets can be used to teach programming. The advantage of these applications is that the surface is familiar to the users and, therefore, a new environment does not have to be introduced. In addition, the syntactic rules of calling the functions are simple, the interpreter provides fast results, so there is no need for time consuming introductory sessions to write syntactically correct codes. Finally, using this familiar environment the students are not necessary aware that they do real programming and consequently, the aversion against programming will not develop.

\section{Teaching Mathematics to Students of Economics \\ Edith Debrenti \\ Partium Christian University, Oradea, Romania \\ E-mail: debrenti_edit@rdslink.ro}

The teaching of mathematics is important not only for the application of the acquired knowledge, but for the development of the logical and rational way of thinking of the students of economics. 
"tmcs-baranyai-report" — 2011/5/16 — 12:55 — page 163 — \#5

A recently appeared article about the role of teaching mathematics in Economical studies points out that mathematics helps in acquiring the knowledge of Economics.

In this presentation I will discuss the application of mathematical exercises in the different domains of economics, proving that all branches of mathematics are needed when economics is viewed in use.

Further on, I would like to share my experience related to a test of initial evaluation that I did with the first year students of economics regarding their skills in mathematics.

Description of a Maple program for creating function analysis problems in written exams

$$
\text { Éva Dékány }
$$

Szent István University, Gödöllő, Hungary

E-mail: dekanykeva@gmail.com

The full analysis of functions is an important and fundamental topic in calculus exams. It is common experience that many students miscalculate or cannot complete the analysis, which results in their getting only a fraction of the full score. Moreover, in such cases the evaluation is difficult for the teacher. Therefore function analysis problems should be split into smaller steps, and this obviously requires a great number of functions. By the help of the program to be introduced in this conference, teachers can easily perform the analysis of many functions. Since the program is still under construction, I would be grateful to you for testing it and also for similar problems to solve.

Conventions of mathematical problems and their solutions Anna K. Fazekas - Sándor Kántor

Teacher Training Secondary Grammar School of Debrecen University, Debrecen, Hungary

E-mail: kfanna@gmail.com

Institute of Mathematics, Debrecen University, Debrecen, Hungary

E-mail: kantors@math.klte.hu

Collecting and analyzing the conventions indispensable for interpreting mathematical problems and their solutions correctly assist successful education and objective evaluation. Many professional and didactical questions arose while collecting and analyzing these conventions, which needed and still need clarification, 


$$
\text { "tmcs-baranyai-report" — 2011/5/16 — 12:55 — page } 164 \text { — \#6 }
$$

therefore the materials involved concisely in the conventions enrich both the theory and practice of mathematics teaching. In our research we concentrated mainly on the problems and solutions of the Hungarian school leaving examinations at secondary level in mathematics. In our presentation we volunteered to show some of the conventions collected, with special emphasis on the controversial ones, hoping to generate a discussion among professionals within and beyond the borders.

\section{Teaching Mathematics using WebWork Peter Fejes Toth \\ University of Debrecen, Debrecen, Hungary \\ E-mail: fejestothpeter@yahoo.com}

WebWork is a free online Mathematics-teaching software which I studied at the University of Calgary. My task was to find out if WebWork helps to learn mathematics. I used several methods: I asked around 700 students to fill out a survey mostly concerning their attitudes towards the program, I collected the results of the Mathematics courses of several years from the Department, I was talking with the members of the Department about their experiences with WebWork, and I myself also used the program and gained experiences with it.

The basic results of the survey are that those who think that they are good at mathematics, those who don't spend too much time with WebWork, and those with a major closely related to mathematics like WebWork more than the others. The comparison of the grades of those who used WebWork and those who have not show that WebWork at least does not worsen the result of the students.

International dimension in the research of mathematics education Ján Gunčaga

Catholic University, Ruzomberok, Slovakia

E-mail: jguncaga@gmail.com

We present some goals of the Seventh Framework Program, part Science in Society. Falling interest in key science topics and mathematics has been linked to the way they are taught from the earliest age. Therefore, greater emphasis needs to be placed on the development of more effective forms of pedagogy; on the development of analytical skills; and, on techniques for stimulating intrinsic motivation for learning science, taking into account various pre-conditions and cultural differences. We present also some parts of the Comenius program such Comenius Training Event, Erasmus Intensive Programme, Comenius Multilateral project. For this purposes it is possible to built the research centre in Levoča 
"tmcs-baranyai-report" — 2011/5/16 — 12:55 — page 165 — \#7

Researches in Didactics of Mathematics and Computer Sciences

(buildings of the Catholic University in Ružomberok), because the city Levoča is near to Hungary, Poland and Ukraine.

\section{Investigation of the structure of some geometrical concepts Eszter Herendiné-Kónya}

Ferenc Kölcsey Teacher Training College of the Reformed Church

E-mail: hke@kfrtkf.hu

One of the main difficulties of the conceptualization is the understanding of hierarchical structure of concepts. Teaching geometry offers many possibilities to demonstrate subordinate and co-ordinate connections between concepts. It is well known, that understanding of these connections is a difficult task for pupils in primary school, because of their age.

Students learn about simple geometrical concepts in primary school and use them not only in lessons of mathematics but in everyday life, too. We were interested in the usage of concept image of students just finished high school. Our research questions are the following:

- What kind of existing knowledge does students have?

- What sort of typical misunderstandings can be recognized?

- What can be the reason of their mistakes?

George Pólya (1887-1985), father of the modern heuristics Tünde Kántor

Institute of Mathematics, University of Debrecen, Debrecen, Hungary

E-mail: tkantor@math.klte.hu

George Pólya made a great impact on mathematicians and mathematics teachers. He was an outstanding researcher and a famous teacher. He reached very important results both in mathematics and even in psychology of mathematical discovery. His books, dealing with heuristics, are actual today.

His heuristical methods are applied not only in mathematics and science but in all kind of research works. He wrote 250 articles and 10 books or monographs. His collected works appeared in 4 volumes (Cambridge, 1974-1984).

Areas of his interest were: Probability, combinatorics, complex and real functions, number theory, theory of algebraic equations, mathematical physics and psychology of mathematical discovery. His most well known books translated into Hungarian are: 


$$
\text { "tmcs-baranyai-report" — 2011/5/16 — 12:55 — page } 166 \text { — \#8 }
$$

1. Aufgaben und Lehrsätze aus der Analysis (with Szegő G.), Springer Verlag, 1924

2. How to solve it? Princeton University Press, 1945

3. Mathematics and Plausible Reasoning I-II., Princeton, Princeton University Press, 1954

4. Mathematical Discovery on Understanding, Learning and Teaching Problem Solving I-II. New York, John Wiley Sons, 1962, 1965

The Galois-graph Analysis of Cognitive Categories in Computer-aided Teaching of Calculus Anna Klingné Takács

Kaposvár University, Faculty of Economic Science, Department of Mathematics and Physics, Kaposvár, Hungary

E-mail: klingne.anna@ke.hu

Mathematics appears as one area of the system of cognitive sciences. Zech and Varga Tamás made didactical researches to work out mathematical targetsystems. My research intends to analyse the appearance of such cognitive categories in teaching Calculus.

Galois-graphs and the universal categories make it possible to enlighten function analysis from a different point of view. We have to strengthen our students' proficiency at the symbolic level, as this level is present throughout the whole process of the task; but according to Bruner's theory, they also need to be familiar with the material and the iconic levels, because problem-solving is much helped by the transition between the different levels. Computer can be a tool of this. They are suitable to be drawn into the work process at the lower levels of the graph, after the occurrence of the category expressing action, as computers also execute commands, operations; this is the reason for introducing them here. According to Varga's cognitive target system of mathematics teaching, it is also the last phase where computers are reasonable to be drawn in. This is helped by applying GeoGebra, because students can use it to check the accuracy of derivation. In cases when the cognitive category 'space' is injured, the use of computers can come at an earlier stage (illustration), the deficiencies experienced during surveying the circumstances of action also call attention to this. Students' proficiency at this category is developed by the use of Excel. 


$$
\text { "tmcs-baranyai-report" — 2011/5/16 — 12:55 — page } 167 \text { — \#9 }
$$

How to Plan our PhD Dissertation? User's Guide for Beginners and Re-beginners

András Kovács

University of Debrecen, Institute of Mathematics, Debrecen, Hungary

E-mail: kovacsa@math.klte.hu

The lecture wants to show the preparing, the planning and the realization of a $\mathrm{PhD}$ dissertation through an imaginary chosen topic. It wants to illustrate with concrete examples, where it is possible the quest of the references and how to take it. The author also speaks about the whole process of the pedagogical experiment. He pans out about the question of the evaluation and summary.

After drawing a lesson the presentation ends with common talking.

The new knowledge base. The secondary mathematics teaching responsibility the foundation subjects in higher education teaching

$$
\text { Ildikó Kozákné Székely }
$$

Attila József Secondary Grammar and Vocational School, Monor, Hungary

$$
\text { E-mail: kiszekely@yahoo.com }
$$

Teaching in secondary school can be a proper frame for increasing the problem solving ability.

Within the frame of this lecture I will present an experiment carried out in order to examine to what extent the explicit teaching of problem solving strategies can enhance the ability of problem solving.

The presentation is bringing forward a summary of how the secondary mathematics teaching contribute to acquiring the necessary knowledge at the foundation subjects - especially mathematics - for higher level education, and what could be done for improving it.

I will also summarize the experiences gained from students who graduated from our school and continued their studies in higher education: how the secondary school mathematics teaching methods help students in the process of acquiring new knowledge at their collegiate studies.

Keywords: Preliminary knowledge, new knowledge, problem-solving strategies, knowledge transfer 


\section{Isogonal transformations of a triangle Péter Körtesi \\ University of Miskolc, Miskolc, Hungary \\ E-mail: matkp@uni-miskolc.hu}

The symmedian lines and the symmedian point of a given triangle present interesting properties. Part of these properties can be formulated in a more general context for isogonals.

In a triangle the isogonal of a line passing through one of the vertices of the triangle is a line symmetric to the bisector of the given angle. It can be proven that the three isogonals of three concurrent lines which pass through the three vertices of the triangle, are concurrent. This property serves as definition for the isogonal transformation, the image of a given point in this transformation will be the intersection point of the three isogonals of the three lines which pass through the given point and the vertices of the triangle. The lecture is aimed to present some of the properties of the isogonal transformations, and to visualise them using GeoGebra.

Cooperative learning in teaching mathematics

$$
\text { Ileana Mate }
$$

The Lower-Secondary School of Paptamasi, Paptamasi, Romania

E-mail: mateilona@yahoo.com

In the course of my teaching experience, I have met such items to be taught that had caused serious difficulties for generations. One of these items is comprised in the $6^{\text {th }}$-grade syllabus: addition and subtraction in the set of integers, with subtraction being the most difficult one. Many adults have a nightmarish memory of the "minus out of minus" rule. The experiment has been conducted in a country school attended by good-intentioned, well-behaved, hardworking pupils who are not selected, elite children.

The main question of the experiment: To what extent do the cooperative method and the use of concrete visual representations make the addition and the subtraction of integers more efficient? 


$$
\text { "tmcs-baranyai-report" — 2011/5/16 — 12:55 — page } 169 \text { — \#11 }
$$

Researches in Didactics of Mathematics and Computer Sciences

Individualized learning

Julianna Mikóné Márton

University of Debrecen, Ph.D. School of Mathematics and Informatics,

Debrecen, Hungary

E-mail: julim@de-efk.hu

When hearing the word "learning", significant part of people comes to mind the traditional form of classroom learning, where the teacher mediates the new knowledge by presentation, and students, sitting in school desk, listening it, and trying to get as much information as he/she can. This picture and this form of passive learning are fading rapidly with the widely spreading of the e-learning systems.

In today's electronic systems numbers of educational opportunities are for the implementation of constructivist pedagogy, active, informal, self-regulated learning. The emphasis is increasingly in self-regulated, personalized learning. This need was brought to life the concept of personalized learning environment (Personalized Learning Environment, PLE).

However, what is it mean? What can be the environment in which personalized, self-regulated learning takes place? What are the requirements of it? What criteria should be taken into account in designing? The presentation will answer these questions along the directives, which allows creating the efficient and effective personalized learning environment.

\section{Language Disadvantage and Mathematics Learning Katalin Munkácsy \\ Eötvös L. University, Budapest, Hungary \\ E-mail: katalin.munkacsy@gmail.com}

The international literature shows that social disadvantage is related statistically significant to the results of school education. Social disadvantage appears as language problems on the mathematics lessons. In normal case development of problem solving skills is parallel to development of symbolic level of mathematics learning. Bruner proposed three modes of representation: enactive representation, iconic representation, and symbolic representation. In our empirical work we gave difficult tasks related to affective mode but our demands were moderate on the level of symbolic mode. In the elementary school we were working with word problems, in the secondary school our topic was the coding and the troubleshoot. Every students could participate in mathematical investigations. Gifted students were on high level of mathematical thinking. The gifted and every other 
students from low SES families need more help to bridges communication gape and to use mathematical symbols.

Comparing the mathematical competences and the school achievement of secondary school students

Ilona Oláhné Téglási

Eszterházy Károly College, Eger, Hungary

E-mail: olahneti@ektf.hu

First I show the idea of mathematical competence and make clear its components. The 2000 Lisbon Resolution of the European Union gave offers to the countries to modernize their educational system. Adding to it the OECD started the PISA-examination, which measures the mathematical competences of the 15-year-olds too. The first the results of Hungarian students were more disadvantageous then we expected. These two events started a development work in our country too, and as a result we now have new types of competence-based school-books, and the methodological culture of teachers is under reformation too. But these changes are not uniformly welcome among teachers. The traditional, content-based teaching has got lots of valuable elements, which are quite actual and have to be saved. In my lecture I show the results of a pre-test done with 278 secondary school students of 4 grades. I made two types of evaluations of the written tests: a traditionally used method, measuring the mathematical achievement, and a new method, measuring the level of mathematical competences. Taking the quotient of the two points, a teacher can see, if the students' mathematical achievement is below, adequate to, or above the level of competences. This qoutient is not difficult to use, and gives more information then the "marks" in school. Upon the results we can declare the main areas of development, and work out development strategies, in which the defects of the knowledge of secondary school students can be supplied, their preparedness can be corrected with the combination of the traditional and new forms, within the given hours and curriculum for mathematics.

\section{Objectivity of the exams Csilla Muhari \\ University of Debrecen, Debrecen, Hungary \\ E-mail: csmuhari@yahoo.com}

The expectation of the objective assessment comes up as a claim in all of the areas of life. Objectivity is important on the workplaces, where employees are 
measured from time to time, and they are waiting for feedback on the effectiveness of their work. Not less important is this in the education, where the feedback from student's performances is an essential condition of the academic achievement.

Studies in higher education became more flexible since the introduction of the Bologna system. The required numbers of credits were provided in expanded borders, the objects built on each other defines the frameworks. Since the introduction of two-level graduation and the elimination of the recruitment procedure students comes with very differing knowledge into BSc/BA trainings.

The lecture examines the opportunities of the solution of the objective assessment with the devices of the informatics inside the domain of the informatics in the higher education

\section{Neumann János és a halmazelmélet megalapozása \\ Péter Tibor Nagy \\ University of Debrecen, Debrecen, Hungary \\ E-mail: nagypeti@math.unideb.hu}

The lecture is devoted to the study of the exciting process of the foundations of set theory in the first decades of the 20th century and emphasized the role of the work of John von Neumann. The basic set-theoretical concepts and propositions are illuminated by schematic analysis of their proofs.

Julius King (Budapest) wanted to disprove the continuum hypothesis of G. Cantor in his lecture at the Mathematics Congress in Heidelberg in 1904. His demonstration contained a logical error which was realized by Zermelo. As a result, he formulated the exact proof of wellordering theorem and has developed an initial system of axioms for set theory. Fraenkel made a critical analysis of this system completing it with the so called replacement axiom.

John von Neumann has treated in his thesis (September 1925, Budapest) is an interesting alternative system of axioms for set theory. His methodological and philosophical motivation was to extend the methods of mathematical logic and set theory for the foundation of whole classical mathematics, in particular for the use of the term of functions. Meanwhile, he has developed the theory of transfinite induction and ordinals. 
"tmcs-baranyai-report" — 2011/5/16 — 12:55 — page 172 — \#14

Interdisciplinary teacher training: The links between pedagogy, mathematics and information technology in teacher training Noémi Szabó Thalmeiner Babeş-Bolyai University, Faculty of Psychology and Pedagogical Sciences, Satu Mare, Romania E-mail: szabothnoemi@yahoo.com

The modern trends in pedagogy schools focus on a holistic view of the world, thus fostering an interdisciplinary approach to teaching, which assumes the collaboration between teachers with different knowledge and skills. The lecture presents a possible practical realisation of such an approach with respect to the pedagogical subjects taught in teacher training (learning methods, pedagogical research, didactics, theory of education, history of education), as well as subjects in mathematics and information technology. Following such collaboration it becomes possible to put into practice the knowledge of mathematics or use of computers, respectively, as well as the development of positive motivation to learning mathematics.

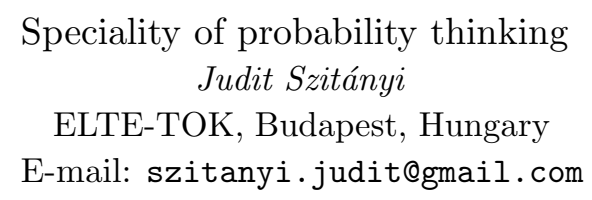

In the last couple of years, I presented the results of a measurement completed among teacher candidates and experiences of lessons recorded during a semester. I looked for the answer during my inspection to the question of the difference between the probability decisions and estimations and thinking strategies applied in other areas of mathematics. I could draw conclusions only about the students' thinking - mathematics is not necessarily in the focus of their interest. The reactions and opinions I perceived during my previous lectures inspired me to repeat my measurements, surveys among student learning mathematics or other natural sciences at university of ELTE. I tried to get more general picture on this way and figure it out how deeply the studies of probabilities have been integrated into thinking of people having graduated.

I would like to summarize my new experiences now. I touch the sameness and differences in probability thinking of graduated people who are interested or not in mathematics. 


$$
\text { "tmcs-baranyai-report" — 2011/5/16 — 12:55 — page } 173 \text { — \#15 }
$$

\author{
Roaming about in geometry land \\ Gabriella Tempfli - Izabella Tomos \\ "Bălcescu Petőfi" Elementary School, Satu Mare \\ E-mail: gtempfli@yahoo.com \\ Elementary School Nr 8, Brasov \\ E-mail: tmsizabella@yahoo.com
}

As teachers of mathematics we have found that most students, who meet with arithmetic, algebra, geometry while in primary or secondary school, are averse to mathematics. It is our task to make our students like and enjoy the subject while developing their logical thinking. If students become aware of the fact that mathematical knowledge has practical use in everyday life, they will feel learning mathematics easier, more interesting and more useful.

Our aim was to present some problems in geometry that could highlight its beauty and usefulness in practice. Those subjects can be taken to the geometry classes as they are related to the compulsory curriculum, or they can constitute the teaching material for an additional optional class.

Our presentation contains the results of a survey we made among the students we teach. Its aim is to measure the extent to which our Roaming about in Geometry Land optional class is liked by the students, as well as to find out how these classes influence the opinion of the students about mathematics and their subsequent approach to learning it.

\title{
Alternatives in the teaching of parallel programming Márk Török - Csaba Biró - Gábor Geda Eszterházy Károly College, Eger, Hungary \\ E-mail: tmark@elte.hu, birocs@aries.ektf.hu, gedag@aries.ektf.hu TÁMOP-4.2.1/B-09/1/KMR-2010-0003
}

Compared to the last few decades, the last couple of years saw dynamic and important changes in the field of processors. From 2005, multi-core processors took the place of the single-core processors computers. During the progress of the parallel computing technology, computing tasks can be solved in no time at all. Thanks to the development of the technologies, in the next years the number of the cores will duplicate. Consequently, the parallel programming technologies will flourish. The parallel programming languages are able to describe and control the on-going processes at a time. Parallel algorithms describe the tasks in question, focusing on the fact that not every task has an efficient solution. Nowadays, to solve tasks such program is more and more required. This fast progress 
brings the education in front of new challanges. We can notice how the parallel programming is being devised in some higher educational institutes around the country. Furthermore, we introduce Cilk++ and TBB, developed by Intel, and we give examples through them, and show the opportunities of how we can tackle parallel programming difficulties.

\section{Abstracts of posters}

The use of cooperative methods for teaching mathematics it the second form

$$
\text { László Ari }
$$

Babeş-Bolyai University, Satu Mare, Romania

E-mail: ari.laszlo@yahoo.com

In my research I am trying to find out what is the influence of using cooperative methods on young students' knowledge, performance and social attitudes.

I have chosen the inductive experimental strategy to prove or to deny the questions and the hypothesis arisen in my project. I used from the group of revealing methods the method of tests and sociometrical tests. I used the tests for measuring the changes in students' level of knowledge, and I used the Sociometrical tests to see how are changing students' social relations.

Two of my previous hypotheses are entirely proved to be true, two of them are proved to be partly correct.

To sum up the results of the experiment, it has been proved that the use of cooperative methods have a positive influence on students' mathematical knowledge level, and it also had an influence on their attitude and social relations. Though it was a short experiment lasting twelve teaching classes, it proved to be more useful than classical teaching methods.

The role of remembrance in the process of learning the multiplication table

\section{Klementina Bartha (Zsebenyi) - Gabriella Martin \\ Babeş-Bolyai University, Satu Mare, Romania \\ E-mail: martingabi72@yahoo.com}

The main query of our research was: "Is pupils' memory connected with the learning process of the multiplication table?" The aim of our research was to find 
out how the state of development of pupils' mind influences the learning process of the multiplication table.

We used the method of inductive experiment to examine the problem. We formed two groups of pupils to perform the experiment. We tested the pupils' knowledge concerning the multiplication table before and after the experiment and compared the results. Pupils of the 3rd form were involved in our research from the general school of Mezőfény and Csomaköz. We elaborated a special programme to develop the memory of the pupils involved in our experimental groups.

Our methods used during the research work were: testing knowledge by worksheets and a psychological method based on questionnaires.

The result of our research was that pupils having a more developed intellectual power got better results in the learning process of the multiplication table. Our memory - developing exercises helped pupils only a little bit. The self - confidence of the pupils did not influence the process of learning at all.

Placement tests and preliminary courses in mathematics in the Faculties of the University of Debrecen

Gábor Csaba Kézi - Adrienn Vinczéné Varga

University of Debrecen, Faculty of Science and Technology, Department of Analysis, Debrecen, Hungary

E-mail: kezicsaba@math.unideb.hu

University of Debrecen, Faculty of Engineering, Department of Basic Subjects of Engineering, Debrecen, Hungary

E-mail: vargaa@math.unideb.hu

In recent years there was a notable rapid decrease of the basic knowledge of mathematics of students of science and technology admitted to higher education institutions.

We carried out tests on various faculties of the University of Debrecen in order to get information on first-year students' knowledge of mathematics which they had gained in high school.

The written tests showed us that there were serious deficiencies in almost all areas of elementary mathematics. Consequently, there is an increasing need for a follow-up course of high school mathematics, thus giving a chance for students to learn the subsequent higher-level mathematics. 
In the Institute of Mathematics, Faculty of Science and Technology, the foundation courses, which were introduced in 2006, "Sets and Functions", "Basic Algebra", "Trigonometry and Coordinate Geometry" serve mainly this purpose.

On the Faculty of Engineering, after passing the fundamental course Basics of Science (which was introduced in 2009, and the major topics of high school mathematics, geometry and physics are discussed) in their first year, students achieved significantly better results later.

In the poster we present the experience gained during the course "Basics of Science". We formulate the current problems of secondary education in the point of view of teachers in higher education teaching science and technology and we make some suggestions what to change.

\section{List of participants}

1) Adrienn Árvainé Molnár, University of Debrecen, Debrecen, Hungary

2) András Ambrus, Eötvös L. University, Mathematics Teaching and Education Centre, Budapest, Hungary, ambrus@cs.elte.hu

3) László Ari, Babeş-Bolyai University, Satu Mare, Romania, ari.laszlo@yahoo.com

4) Tünde Baranyai, Babeş-Bolyai University, Faculty of Psychology and Educational Sciences, Satu Mare, Romania, baratun@yahoo.com

5) Klementina Bartha Zsebenyi, Babeş-Bolyai University, Satu Mare, Romania

6) Csaba Bíró, Eszterházy Károly College, Eger, Hungary, birocs@aries.ektf.hu

7) Ignác Bontovics, SZIE - PK, Szarvas, Hungary, bignacz@gmail.com

8) Mária Csernoch, University of Debrecen, Faculty of Informatics, Debrecen, Hungary, csernoch.maria@inf .unideb.hu

9) Edith Debrenti, Partium Christian University, Oradea, Romania, debrenti_edit@rdslink.ro

10) Éva Dékány, Szent István University, Gödöllő, Hungary, dekanykeva@gmail.com

11) Anna K. Fazekas, Teacher Training Secondary School of Debrecen University, Debrecen, Hungary, kfanna@gmail.com 
12) Sarolta Fazekas, University of Debrecen, Debrecen, Hungary, sarolta.fazekas@gmail.com

13) Peter Fejes Toth, University of Debrecen, Debrecen, Hungary, fejestothpeter@yahoo.com

14) Gábor Geda, Eszterházy Károly College, Eger, Hungary, gedag@aries.ektf .hu

15) Ján Gunčaga, Catholic University in Ružomberok, Faculty of Education, Department of Mathematics, Ružomberok, Slovak Republic, jguncaga@gmail.com

16) Eszter Herendiné Kónya, Kölcsey F. Teacher Training College of the Reformed Church, Debrecen, Hungary, hke@kfrtkf .hu

17) Tünde Kántor, University of Debrecen, Institute of Mathematics, Debrecen, Hungary, tkantor@math.klte.hu

18) Sándor Kántor, University of Debrecen, Institute of Mathematics, Debrecen, Hungary, kantors@math.klte.hu

19) Gábor Csaba Kézi, University of Debrecen, Faculty of Science and Technology, Department of Analysis, Debrecen, Hungary, kezicsaba@math.unideb.hu

20) Sándor Kiss, Wooden Industrial Lyceum, Satu Mare, Romania, kissandor@clicknet.ro

21) Anna Klingné Takács, University of Kaposvár, Faculty of Economic Science, Department of Mathematics and Physics, Kaposvár, Hungary, klingne.anna@ke.hu

22) Judith Kollár, University of Debrecen, Debrecen, Hungary, zolna1@freemail.hu

23) Éva Kopasz, Eötvös J. College, Baja, Hungary, kopaszevaemese@gmail.com

24) András Kovács, University of Debrecen, Institute of Mathematics, Debrecen, Hungary, kovacsa@math.klte.hu

25) Ildikó Kozákné Székely, Attila József Secondary Grammar and Vocational School, Monor, Hungary, kiszekely@yahoo.com

26) Péter Körtesi, University of Miskolc, Miskolc, Hungary, matkp@uni-miskolc.hu

27) Sándor Kristály, Babeş-Bolyai University, Faculty of Economics, Sfăntu Gheorghe, Cluj Napoca, Romania, alexandrukristaly@yahoo.com 
28) Károly Lajkó, College of Nyíregyháza, Nyíregyháza, Hungary, lajko@math.klte.hu

29) Gyula Maksa, University of Debrecen, Institute of Mathematics, Debrecen, Hungary, maksa@math.klte.hu

30) Gabriella Martin, Babeş-Bolyai University, Satu Mare, Romania, martingabi72@yahoo.com

31) Ileana Mate, The Lower-Secondary School of Paptamasi, Paptamasi, Romania, mateilona@yahoo.com

32) Julianna Mikóné Márton, University of Debrecen, Ph.D. School of Mathematics and Informatics, Debrecen, Hungary, julim@de-efk.hu

33) Csilla Muhari, University of Debrecen, Ph.D. School of Mathematics and Informatics, Debrecen, Hungary, csmuhari@yahoo.com

34) Katalin Munkácsy, Mathematics Teaching and Education Centre, Budapest, Hungary, katalin.munkacsy@gmail.com

35) Péter Nagy Tibor, University of Debrecen, Debrecen, Hungary nagypeti@math. unideb.hu

36) Ilona Oláhné Téglási, Eszterházy Károly College, Eger, Hungary, olahneti@ektf .hu

37) Zsolt Páles, University of Debrecen, Institute of Mathematics, Debrecen, Hungary, pales@math.klte.hu

38) Gabriella Stark, Babeş-Bolyai University, Faculty of Psyhology and Educational Sciences, Satu Mare, Romania, ngabriella77@yahoo.com

39) Noémi Szabó Thalmeiner, Babeş-Bolyai University, Faculty of Psyhology and Educational Sciences, Satu Mare, Romania, szabothnoemi@yahoo.com

40) Ibolya Szilágyiné Szinger, Eötvös J. College, Baja, Hungary, szilagyine.szinger.ibolya@ejf.hu

41) Judit Szitányi, ELTE-TOK, Budapest, Hungary szitanyi.judit@gmail.com

42) Gabriella Tempfli, "Bălcescu Petőfi" Elementary School, Satu Mare, Romania, gtempfli@yahoo.com

43) Izabella Tomos, Elementary School Nr 8, Brasov, Romania, tmsizabella@yahoo.com

44) Csaba Varga, Babeş-Bolyai University, Faculty of Geometry, Cluj Napoca, Romania, csvarga@nessie.cs.ubbcluj.ro 
"tmcs-baranyai-report" — 2011/5/16 — 12:55 — page 179 — \#21

45) Adrienn Vinczéné Varga, University of Debrecen, Faculty of Engineering, Department of basic subjects of Engineering, Debrecen, Hungary,

vargaa@math.unideb.hu

TÜNDE BARANYAI

BABES-BOLYAI UNIVERSITY

FACULTY OF PSYHOLOGY AND EDUCATIONAL SCIENCES

PETÖFI SÁNDOR STR. 47.

SATU MARE

ROMANIA

E-mail: baratun@yahoo.com

ESZTER HERENDINÉ KÓNYA

KÖLCSEY F. TEACHER TRAINING COLLEGE OF THE REFORMED CHURCH

PÉTERFIA STR. 1-7.

DEBRECEN

HUNGARY

$\mathrm{H} 4026$

E-mail: hke@kfrtkf.hu

(Received March, 2011) 